\title{
Contribution and dilemmas of Medical undergraduate students in combating disease outbreaks: COVID 19 and previous outbreaks
}

This article was published in the following Dove Press journal:

Advances in Medical Education and Practice

Jayanti Pant $\mathbb{D}^{\prime}$

Mahendra Kumar Pant $\mathbb{D}^{2}$

Manisha Naithani $\mathbb{D}^{3}$

'Department of Physiology, All India Institute of Medical Sciences, Rishikesh

249203, Uttarakhand, India; ${ }^{2}$ Department of Anatomy, Government Doon Medical College, Dehradun 24800I, Uttarakhand, India; ${ }^{3}$ Department of Biochemistry, All India Institute of Medical Sciences, Rishikesh 249203, Uttarakhand, India

\begin{abstract}
COVID 19 has brought several challenges for each individual, changing the world's perception of health-care professionals. People are hailing health-care professionals as heroes, worthy of praise and gratitude. However, the pandemic has overburdened the health-care system. In this situation, the undergraduate medical students are being used as a crucial part of the health-care team in various ways. Involvement of medical undergraduates in situations of natural disaster is not new. In fact, a review of history of previous natural disasters reveals that this has been normal every time health systems have been overburdened. In the present situation of COVID 19, these students have a crucial role to play in helping frontline workers combat the crisis. Though the students would like to render their services, they are in a state of dilemma, as their roles are not defined clearly and their training to combat the pandemic is inadequate, as it was in previous outbreaks. This highlights a need to introduce module-based training for medical graduates to contribute effectively in combating future outbreaks.
\end{abstract}

Keywords: pandemic, outbreaks, medical students, services, undergraduate

\section{Introduction}

Disease outbreaks in the form of pandemics and epidemics have been affecting humanity for centuries, and with each outbreak mankind has evolved progressively. These outbreaks arise and spread across large areas involving different countries and continents and potentially affecting many people. In history, outbreaks of diseases like smallpox, tuberculosis, plague, Spanish flu, influenza, Ebola, HIV/ AIDS, and Polio resulted in death tolls that were immense and widespread. ${ }^{1}$ At present, the world is facing the COVID 19 pandemic, with a frightening spectrum of widespread infection and mounting mortality. The pandemic has infected $17,918,582$ people, leading to the loss of 686,703 lives across the world at present. ${ }^{2}$

The COVID 19 pandemic has made apparent some deficiencies in prevailing health-care systems. Even in the most developed countries, the ability to handle outbreaks effectively is questionable, as evidenced by the current situation. This is a major setback to the medical community. Saving lives in the current pandemic without available treatment has presented the biggest challenge to health-care workers internationally. ${ }^{3}$ There have been several preventive measures adopted, such as maintaining hand hygiene, social distancing, lockdown practices, use of antimalarial drugs, use of antiretroviral drugs, use of personal protective equipment,
Correspondence: Manisha Naithani Department of Biochemistry, All India Institute of Medical Sciences, Rishikesh, 249203, Uttarakhand, India Email naithanimanisha@gmail.com
Advances in Medical Education and Practice 2020:II 66I-667 
isolation, quarantine, and intensive-care treatment, but our battle against this viral infection continues. ${ }^{3,} 4$ Amid all these practices, it is imperative to understand that the health-care workers acting as frontline warriors against the pandemic are under tremendous workload and psychological pressure. ${ }^{5}$ Many health-care providers have been infected, and some have even lost their lives.

As such, the pandemic has put considerable burden on the health-care system. Not only there is a need to establish a cure but there is also a need for manpower that can directly or indirectly help health-care workers in the frontline. In various countries, different medical schools have recruited their medical undergraduate students to serve this purpose. Involvement of students during pandemics is not a new strategy, but has been used each time the medical community faced outbreaks and natural disasters, and it is important to understand how medical undergraduates have provided their valuable services during these emergencies. In the present review, we analyze the role of medical undergraduates in previous outbreaks and also envisage their role in the present COVID 19 pandemic. Further, their dilemmas in these unexpected situations are also highlighted.

\section{8-1919 Spanish Flu Pandemic}

The Spanish flu pandemic emerged in 1918. The University of Sydney and the Royal North Shore Hospital helped save the lives of people affected by the flu and played an important role during the pandemic. The pandemic infected $>500$ million people across the globe, and $>50$ million people lost their lives. ${ }^{6}$ During this pandemic, the Australian government issued orders to close all public places and avoid gatherings. The University of Sydney accordingly suspended teaching classes and closed schools. Medical students and teachers voluntarily worked in hospitals and health centers. ${ }^{6}$ Similarly, in Philadelphia in 1918 at the University of Pennsylvania School Of Medicine, classes were suspended and third- and fourthyear medical students assigned to patient-care duties. As described by one of the students, they had a single lecture on influenza before the suspension of their classes and subsequent assignment of clinical duties. The mortality rate was very high at that time. ${ }^{7}$ Some of the medical students had graduated early and were pressurized to contribute as health-care personnel in the US during the pandemic. These students worked on their own without much supervision from senior doctors. The extraordinary efforts of students have been recorded over history, with few surviving the pandemic and sharing their struggles with the world. Wallace Freeborn (1898-1971) was one of the medical students who volunteered as a Red Cross worker. He later on became the General Medical Superintendent at Royal North Shore Hospital in $1948 .^{6}$

\section{2-1953 Danish Poliomyelitis Epidemic}

Denmark witnessed an epidemic of polio in 1952-1953, labeled the worst epidemic in the history of Europe. Patients infected with polio presented with varied symptoms, including paralysis and respiratory failure. Anesthetist Bjørn Ibsen and his colleagues from other specialities in HCA Lassen's Department of Communicable Diseases at Copenhagen's Blegdamshospitalet introduced a technique of manual intermittent positive-pressure ventilation. He was assisted by $>1,500$ medical students in providing ventilation to the large number of patients resulting from the epidemic. Their efforts paid off, and the mortality rate of $87 \%$ was reduced to $26 \%$ with use of this technique. ${ }^{8}$

\section{Influenza Pandemics of 2003 and 2009}

During the H5N1 influenza pandemic, students wanted to provide their services; however, medical school administration authorities in most places were not ready to risk student lives. A survey conducted at the University of Michigan Medical School and Health System revealed that $88 \%$ of students considered that they should be incorporated into services during pandemics and that they act as important first responders participating voluntarily. ${ }^{9}$ In another questionnaire-based study, it was reported that most students believed that they had an obligation to volunteer during a pandemic. ${ }^{10}$ Toner and Walderhorn suggested that medical and nursing students must be used to provide help to hospital staff during influenza pandemics in some way. ${ }^{11}$ However, a different school of thought also prevailed: keeping students at the forefront would unnecessarily put them at increased risk of contracting illness, eventually leading to loss of promising future health professionals. In Toronto, when there was an escalation in patients with severe acute respiratory syndrome, medical students were removed from hospital duties to prevent undue exposure. ${ }^{12}$ Similarly, during the severe acute respiratory syndrome outbreak in China, clinical teaching was halted after 17 students contracted the disease. ${ }^{13}$ In a study conducted with Belgian senior medical students, $82 \%$ affirmed that they would care for pandemic patients if necessary; however, only $42 \%$ agreed to care for pediatric patients. ${ }^{14}$ This study brought to light 
that students were not confident enough to take care of special subsets of patients in times of emergency.

\section{AIDS Epidemic}

The AIDS epidemic claimed many lives. Unlike the influenza pandemic, in the AIDS epidemic medical students were called upon to provide services in active patient care. In 1985, at Bellevue Hospital, New York, due to the rising number of hospital patients, each patient was assigned a medical team comprising a physician, a resident, two interns, and two fourth-year medical students. ${ }^{15}$

\section{Ebola Epidemic}

When the Ebola epidemic appeared in Africa in 2018, medical students helped to make people aware of the disease. The Congolese were suspicious about receiving medical help from Western health-care professionals and showed resistance. As such, the Congolese government deployed 600 medical students to spread of awareness to approximately 10,000 people in the community. These students motivated people to come to health-care centers for examination and treatment. ${ }^{16}$

\section{Students' Roles in Other Disasters}

History has witnessed medical students providing exemplary services during natural disasters and terrorist attacks, in addition to disease outbreaks. During the terrorist attacks in New York City on September 11, 2001, medical students helped voluntarily without any mandate from the government to do so. ${ }^{17}$ On the contrary, during Hurricane Rita, college administration at Texas A\&M University College of Medicine canceled classes and provided students with orientation classes so that they could volunteer. ${ }^{17}$ A limited number of students volunteered for the services. They reported feeling agitated that their inadequate knowledge in the subject made a proper contribution unlikely. However, all students agreed that the experience made them even more oriented to their profession. ${ }^{17}$

In 2005, there was a massive earthquake in Pakistan and some parts of India and Afghanistan. Pakistan deployed final-year medical students for disaster management. However these students faced several difficulties in managing clinical cases without any supervision. They later recounted such difficulties as an inability to treat children, confusion in prioritizing medical attention, and keeping check on emotional aspects and many also faced severe injuries. ${ }^{18}$ Further, in July 2005 a heavy downpour of $>944 \mathrm{~mm}$ rain in a day resulted in devastating floods in
Mumbai, India. It was one of the heaviest rainfalls recorded in 90 years. Mumbai had increasing numbers of patients with leptospirosis during the floods. KEM hospital, Mumbai deployed teams comprising undergraduate students. These students rendered services by contributing to blood collection and furnishing laboratory reports of the patients. ${ }^{19}$

\section{Medical Undergraduates and COVID 19}

The COVID 19 pandemic has encircled the entire world in a short time. The escalating patient numbers have overburdened health-care professionals across the globe and given rise to a manpower shortage to manage the pandemic. In the present situation, medical schools are deploying medical students as an important addition to frontline health-care providers. Clerkship rotations of third-year students have been canceled in various medical schools, and preclinical subjects are being taught through online classes. In Italy and the UK, graduation ceremonies have been canceled and replaced by virtual expedited ceremonies so that students can provide services as doctors. ${ }^{20,21}$ Finalyear students in many medical schools are being asked to graduate early so that they may join the active workforce. ${ }^{21}$ Over 13 medical schools in the US have allowed students to graduate early and provide services in active patient management and care. ${ }^{22}$ The steps taken by medical schools are comparable to those taken during previous outbreaks.

Students at the University of Southern California are involved in running phone call-based information centers, and students of the University of Minnesota are providing child care for frontline health-care professionals. ${ }^{23}$ Further, students of East Tennessee State University are helping to screen COVID-19 patients. $^{23}$ Students of the University of Pittsburgh are delivering medications to high-risk patients. Georgetown University students have created a personal protective-equipment drive. ${ }^{23}$ Harvard Medical School students have formed a team and further constituted four different committees to support hospital staff with services like providing child care, shopping for groceries, propagating educational materials and music videos, developing the medical student clinical workforce, preparing a database on various initiatives of different medical schools in US, and caring for homeless and older patients. ${ }^{24}$

Similarly, Stanford medical students have developed a website on COVID 19 to answer $>85$ FAQs and any new queries that are being thoroughly researched and answered by a team of students. However, they are not involved in direct patient care at present. Some students are involved in collection drives, whereas some have designed face 
shields as personal protective equipment. ${ }^{25}$ At Oxford medical school, 24 medical students have voluntarily joined the emergency department to aid patient care. After initial training, they are being deployed for services like directing patients, attending the reception desk, and performing blood tests, electrocardiography, and other diagnostic tests. ${ }^{26}$

In India, the medical college in Odisha has trained approximately 500 MBBS students to treat COVID 19 patients when their services are needed. ${ }^{27}$ Some medical students in Uttar Pradesh (India) are reported to be engaged in spreading awareness about the pandemic in villages, even in scorching summer temperatures and Ramadan fasting. ${ }^{28}$ Further, third- and fourth-year students of medical colleges in Maharashtra (India) have been asked to provide services on a voluntary basis. The government has agreed to initiate paid voluntary services and deduction of duty periods in the present pandemic from their mandatory service-bond period. ${ }^{29}$ Medical students in the Czech Republic have voluntarily provided their services in this pandemic. ${ }^{30}$

Third-year medical students at the Heritage College of Osteopathic Medicine in Ohio are being posted mandatorily to assist in COVID 19 public health care. ${ }^{31}$ Russian medical students are being mandated to provide services in COVID wards. ${ }^{32}$ A questionnaire-based study from Dow Medical College, Karachi revealed that $78 \%$ students felt obliged to take care of the patients and were ready to serve, whereas $75 \%$ were worried about getting infected. ${ }^{33}$ These students are facing varied emotional dilemmas and uncertain about their own protection from infection. Amid fear, many medical students in the US are voluntarily lending their services by working in call centers for patients and acting as first responders. Many of these students raise funds and arrange protective equipment.

\section{Discussion}

Medical undergraduates are under an unusual amount of stress and confusion. They are unsure about their future because of suspension of classes and the issue of lockdown, with their entire curriculum shifted to online classes. However, learning medicine is not all just knowledge, but also skill and online classes would be covering only the lowest rung of Miller's Triangle, only the knowledge portion of Bloom's taxonomy and would be only one of six ACGME (Accreditation Council for Graduate Medical Education) core skills required to be fulfilled by a medical graduate. ${ }^{34}$ Communication skills, attitudes, empathy, altruism, professionalism, and humanities cannot be learned through virtual media. However, the present COVID 19 pandemic has affected everything, and efforts are being made to devise new and innovative ways to come out of this challenging situation everywhere in the world.

Experience from past outbreaks has taught us that medical undergraduates may be deployed as an indirect task force. It is clear that their role in the present pandemic is no different from previous episodes. The students are untrained as far as outbreak/disaster management is concerned. Like previous outbreaks, they are still receiving fast-track training on handling the pandemic without learning the intricacies of its management. They are forced to join frontline workers at many places, repeating the history of Spanish flu pandemic. Despite the evolution of medicine in the present era, active training for management of outbreaks has not yet been incorporated in the undergraduate curriculum. The students are as naïve, as they were in the past, merely studying a few chapters on outbreaks mentioned in their textbooks. There are no clear guidelines defining their role in the present pandemic, a state that is quite similar to that in past. The message is clear that students are untrained and hence feel unconfident and apprehensive in providing active patient care. Therefore, precautions must be taken while allotting tasks to these students so that they are not under threat. The most important point to be considered is that untrained students' help would be more of a catastrophe, leading to wasting of resources. On the contrary, these students may be of great help if they are assigned responsibilities they can handle with alacrity like taking detailed histories of patients, attending to calls of patients, helping in understaffed clerical departments, providing food and medicines to patients and frontline workers, taking care of older people, and helping to develop online help desks. Junior students who are at home may help spread the message to the public about practicing social distancing, use of masks, and how to prepare masks at home through an online platform. The KAP (knowledge, attitudes, and practice) studies conducted in different medical schools across the world have revealed for example that $>80 \%$ of Jordanian medical students have adequate knowledge about the pandemic and are adopting correct practices during this period. ${ }^{35} \mathrm{~A}$ further survey in Ugandan medical students revealed that $91 \%$ had good knowledge about the pandemic, $74 \%$ a positive attitude, $57 \%$ good practices, and $80 \%$ of students were ready to volunteer in frontline care, ${ }^{36}$ while $96.6 \%$ of medical students at an Indian medical school reported practicing increased hand-washing during the pandemic, $92.7 \%$ had appropriate knowledge of COVID-19, and $>80 \%$ had a positive attitude toward COVID-19. ${ }^{37}$ Another 
study reported inadequate knowledge and practices in healthcare workers, including medical undergraduates, in India. ${ }^{38}$ These studies show that these students can assist frontline workers in several ways. It is important that ethical concerns be taken care of while deploying students during the pandemic, as explained by the American Association of Medical Colleges. Foremost is the voluntary nature of deployment, delegating work with minimal risk, the kind of work allotted to the students should be according to their training with minimum risk of exposure, they must be provided with adequate personal protective equipment, they have to be supervised, and above all the services must be voluntary and not imposed. ${ }^{39}$ Unplanned deployment as frontline workers without adequate training may lead to adverse incidents and probably loss of medical leaders who would have come out of pandemics with more experience and wisdom.

Further, in contrast to previous outbreaks, in many countries students in the present pandemic have taken up these responsibilities in a very dignified manner. Such voluntary services can be attributed to advancement in the field of information technology. Unlike previous outbreaks, students in the present pandemic are able to take up unconventional roles of managing call centers, running websites, tracking solitary elderly people, preparing personal protective equipment, and many more. Medical students' desire to contribute to combating the pandemic must be appreciated, but we must remember the predicament of those posted in the front line without proper skills or training. Also, there is growing aggression and restlessness, as they are not sure about their future. The ones who are left with a few months to graduation are stressed about their role in the pandemic once they start working. Many of these students have voluntarily chosen to graduate early and help frontline workers directly.

The present pandemic obliges us to rethink medical curricula followed across the globe. Special training to deal with disease outbreaks and natural disasters must be incorporated in routine medical curricula so that medical students are better prepared to aid and eventually lead health-care teams. Several medical schools, including Harvard Medical School, the University of Colorado School of Medicine, and the University of Vermont College of Medicine, have been running pandemicpreparedness exercises after influenza pandemics, ${ }^{40}$ and similar training protocols must be implemented in all medical schools. Such outbreak-preparedness curricula may be distributed across different years of medical study. For example, first-year medical undergraduates may be given training on handling call centers and help desks, preparing posters/pamphlets, and spreading awareness campaigns. Second-year students may be trained in history-taking, collecting samples, data entry, and handling websites. Thirdand final-year students may be trained for basic patient management, documentation, and counseling. Such outbreak-management curricula may be followed uniformly in all medical schools across the globe. Such steps would ensure that students know their exact role during conditions of crisis according to the year of graduation and render their services without any state of confusion and panic.

Presently, health-care professionals across the globe have immense responsibility to save mankind from the clutches of this deadly virus. This entails significant workload and stress for frontline workers. In this challenging situation, medical students may be used to reduce some workload directly or indirectly from frontline workers. Efforts should be focused on the students rendering their services effectively and safely.

\section{Conclusion}

Medical undergraduates have a record of providing valuable services during disease outbreaks; however, the previous outbreaks and the present COVID 19 pandemic have shown that they need to be trained in advance and must be aware of their specific roles so that they are not in dilemma or dismay. Previous disasters have been a learning experience such that the same mistakes should not be repeated for the present pandemic and medical students' services could be used more judiciously.

\section{Disclosure}

The authors report no conflicts of interest in this work.

\section{References}

1. Chughtai A. From the plague to MERS: a brief history of pandemics. What you need to know about the other pandemics that shook the world; 2020. Available from: https://www.aljazeera.com/indepth/inter active/2020/05/plague-mers-history-pandemics-200520124051021. html. Accessed June 3, 2020.

2. COVID-19 Worldwide Dashboard. WHO Live World Statistics. 2020.

3. Treatments for COVID-19. What helps, what doesn't, and what's in the pipeline. Available from: https://www.health.harvard.edu > dis eases-and-conditions > treatments-for. Accessed June 3, 2020.

4. Prevention of COVID-19. World Health Organization who.int. Available from: www.who.int/covid-19/information. Accessed June 3, 2020.

5. Dubey S, Biswas P, Ghosh R, et al. Psychosocial impact of COVID-19. Diabetes Metab Syndr. 2020;14(5):779-788. doi:10.1016/j.dsx.2020. 05.035 
6. Medical school history: the 1919 influenza pandemic; 2019. Available from: https://www.sydney.edu.au > news-and-events > 2019/10/22 > medical-sch. Accessed June 3, 2020.

7. Starr I. Influenza in 1918: recollections of the epidemic in Philadelphia. 1976. Ann Intern Med. 2006;145(2):138-140. doi:10.7326/0003-4819-145-2-200607180-00132.

8. Trubuhovich RV. In the beginning. The 1952-1953 Danish epidemic of poliomyelitis and Bjørn Ibsen. Crit Care Resusc. 2003;5:227-230.

9. Waight G, Berhane A, Orton L, Cinti S, Billi JE, Kim CS. The role of the medical students in influenza pandemic response. J Emerg Manag. 2011;9(2).

10. Rosychuk RJ, Bailey T, Haines C, et al. Willingness to volunteer during an influenza pandemic: perspectives from students and staff at a large Canadian university. Influenza Other Respir Viruses. 2008;2 (2):71-79. doi:10.1111/j.1750-2659.2008.00042.x

11. Toner E, Waldhorn R. What hospitals should do to prepare for an influenza pandemic. Biosecur Bioterror. 2006;4(4):397-402. doi:10. 1089/bsp.2006.4.397

12. Clark J. Fear of SARS thwarts medical education in Toronto. BMJ. 2003;326(7393):784. doi:10.1136/bmj.326.7393.784/c.

13. Loh LC, Ali AM, Ang TH, Chelliah A. Impact of a spreading epidemic on medical students. Malays J Med Sci. 2006;13(2):30-36.

14. Mortelmans L, De Cauwer H, Van Turnhout E. Suitability of Belgian medical students to act in $\mathrm{H} 5 \mathrm{~N} 1$ pandemic: are Belgiansenior medical students ready to deliver basic medical care in case of a $\mathrm{H} 5 \mathrm{~N} 1$ pandemic? Prehosp Disaster Med. 2009;24(5):438-442. doi:10.10 17/S1049023X00007287

15. Sullivan R. AIDS: bellevue tries to cope with disease it cannot cure; 1985. Available from: https:/www.nytimes.com/1985/12/23/us/aidsbellevue-tries-to-cope-with-disease-it-cannot-cure.html. Accessed May $27,2020$.

16. 2018 Ebola outbreak in Congo provides public health lessons for COVID-19, say researchers. Available from: https://www.folio.ca > 2018-ebola-outbreak-in-congo-provides-public-heal. Accessed May 26, 2020.

17. Herman B, Rosychuk RJ, Bailey T, Lake R, Yonge O, Marrie TJ. Medical students and pandemic influenza. Emerg Infect Dis. 2007;13 (11):1781-1783. doi:10.3201/eid1311.070279

18. Sabri AA, Qayyum MA. Why medical students should be trained in disaster management: our experience of the Kashmir earthquake. PLoS Med. 2006;3(9):e382. doi:10.1371/journal.pmed.0030382

19. Kshirsagar NA, Shinde RR, Mehta S. Floods in Mumbai: impact of public health service by hospital staff and medical students. JPGM. 2006;52(4):312-314.

20. Goldberg E A medical class 'minted by the pandemic'. The New York Times. 25 March 2020 Accessed May 26, 2020.

21. Khamees D, Brown CA, Arribas M, Murphey AC, Haas MR, House JB. In crisis: medical students in the COVID-19 pandemic. AEM Educ Train. 2020;4(3):284-290. doi:10.1002/aet2.10450

22. Abrams A, Ducharme J. COVID-19 is turning medical students into doctors early. Time; 2020. Available from: https://time.com > Health > COVID-19. Accessed May 27, 2020.

23. Mussard C. Med students find creative ways to help during pandemic. AAFP; 2020. Available from: https://www.aafp.org > news > opinion > 20200409guested-students. Accessed May 27, 2020.

24. HMS. COVID-19 student response team. Available from: https:// hms.harvard.edu > coronavirus-updates > hms-responds-coronavirus. Accessed June 1, 2020.

25. Not yet able to treat patients, stanford medical students help caregivers.Available from: https://med.stanford.edu/news/all-news/ 2020/04/medical-students-lend-a-hand.html. Accessed June 1, 2020.
26. Oxford medical students step-up to support fight against Covid-19. Available from: http://www.ox.ac.uk/news/2020-03-23-oxfordmedical-students-step-support-fight-against-covid-19. Accessed June 1,2020 .

27. Odisha trains 500 MBBS students to treat COVID-19 patients. Available from: https://www.deccanherald.com/national/east-andnortheast/odisha-trains-500-mbbs-students-to-treat-covid-19-patients -821189.html. Accessed June 2, 2020.

28. UP medical students spread awareness about covid-19 in villages. NDTV News. Available from: https://www.justdial.com/JdSocial/ news/Top-Stories-generic/UP-Medical-Students-Spread-AwarenessAbout-COVID19-In-Villages/1588389853315025?dl=1. Accessed June $1,2020$.

29. Mumbai: after Cooper, KEM, Nair call in medical students for Covid-19 duty. Available from: https://timesofindia.indiatimes.com/ city/mumbai/mumbai-after-cooper-kem-nair-call-in-medical-students -for-covid-19-duty/articleshow/76114680.cms. Accessed September 2,2020 .

30. Kottasová I. Thousands of medical students are being fast-tracked into doctors to help fight the coronavirus CNN. Available from: https:/edition.cnn.com/2020/03/19/europe/medical-studentscoronavirus-intl/index.html. Accessed June 1, 2020.

31. Heritage college students to lend a hand in fighting pandemic. Available from: https://www.ohio.edu/news/ 2020/04/heritage-college-studentslend-hand-fighting-pandemic. Accessed June 2, 2020.

32. Russian medical students 'forced' to work in coronavirus wards. Available from: https://www.thenational.ae/world/europe/russianmedical-students-forced-to-work-in-coronavirus-wards-1.1017765. Accessed June 2, 2020.

33. Ahmed N, Khan A, Naveed AH, Moizuddin SM. Concerns of undergraduate medical students towards an outbreak of covid-19. Int J Med Pharm Case Reports. 2020;6(03(A)):5055-5062.

34. Core competencies: graduate medical education. Available from: http://med.stanford.edu/gme/housestaff/current/core-competencies. html. Accessed June 2, 2020.

35. Khasawneh AI, Humeidan AA, Alsulaiman JW, et al. Medical students and COVID-19: knowledge, attitudes, and precautionary measures. a descriptive study from Jordan. Front Public Health. 2020;8:253. doi:10.3389/fpubh.2020.00253

36. Olum R, Kajjimu J, Kanyike AM, et al. Perspective of medical students on the COVID-19 pandemic: survey of nine medical schools in Uganda. JMIR Public Health Surveill. 2020;6(2):e19847. doi:10. 2196/19847

37. Maheshwari S, Gupta PK, Sinha R, Rawat P. Knowledge, attitude, and practice towards coronavirus disease 2019 (COVID-19) among medical students: a cross-sectional study. J Acute Dis. 2020;9 (3):100-104. doi:10.4103/2221-6189.283886

38. P D M, Nair G, Uppe A, et al. COVID-19 awareness among healthcare students and professionals in Mumbai metropolitan region: a questionnaire-based survey. Cureus. 2020;12(4):e7514. doi:10.7759/ cureus. 7514

39. Graduating early to join the physician workforce. Available from: https://www.ama-assn.org/delivering-care/ethics/graduating-earlyjoin-physician-workforce. Accessed July 28, 2020.

40. Carney JK, Schilling LM, Frank SH, et al. Planning and incorporating public health preparedness into the medical curriculum. Am J Prev Med. 2011;41(4S3):S193-199. doi:10.1016/j.amepre.2011. 05.026 


\section{Publish your work in this journal}

Advances in Medical Education and Practice is an international, peerreviewed, open access journal that aims to present and publish research on Medical Education covering medical, dental, nursing and allied health care professional education. The journal covers undergraduate education, postgraduate training and continuing medical education including emerging trends and innovative models linking education, research, and health care services. The manuscript management system is completely online and includes a very quick and fair peer-review system. Visit http://www.dovepress.com/testimonials.php to read real quotes from published authors.

Submit your manuscript here: http://www.dovepress.com/advances-in-medical-education-and-practice-journal 